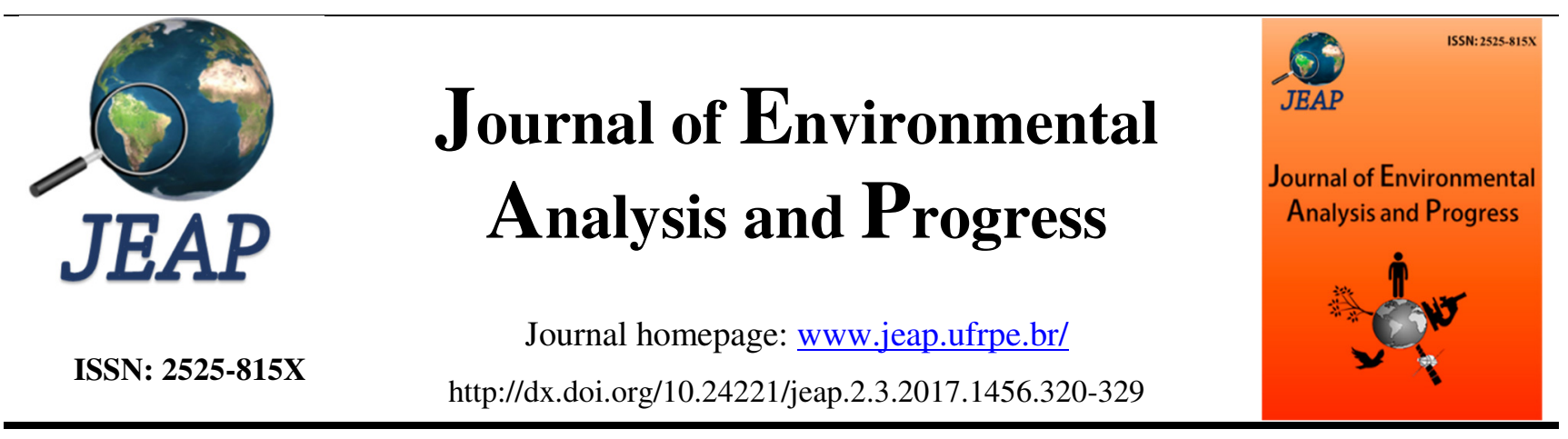

\title{
Características fisiológicas e componentes de produção de feijão caupi sob diferentes lâminas de irrigação
}

\section{Physiological characteristics and production components of cowpea under different irrigation depths}

\author{
Iris Santana Gonçalves ${ }^{\mathrm{a}}$, Rodrigo Rafael da Silva ${ }^{\mathrm{a}}$, Gertrudes Macário de Oliveira ${ }^{\mathrm{a}}$, Edgo Jackson \\ Pinto Santiago ${ }^{\text {a }}$, Vinícius Evangelista Alves de Oliveira ${ }^{a}$ \\ ${ }^{a}$ Universidade do Estado da Bahia-UNEB, Avenida Edgar Chastinet, s/n, São Geraldo, Juazeiro-BA, CEP: $48905-680$. \\ E-mail: irissg@hotmail.com.
}

\begin{abstract}
A R T I C L E I N F O
Recebido 30 Jun 2017

Aceito 22 Jul 2017

Publicado 31 Jul 2017

A B S T R A C T

Cowpea has genetic potential to reach high yields if irrigated, but water deficiency is one of the most limiting factors of grain production. Considering that different genotypes of cowpea react in different forms to water application and climatic conditions in which they are submitted. The objective of this study was to evaluate physiological characteristics and the components of production of cowpea under different irrigation depths, in sub middle of the São Francisco Valley. The experiment was conducted in the experimental area of the DTCS / UNEB, Juazeiro, from July to September 2016. The experimental design was in randomized blocks, with three replicates. The genotypes of cowpea BRS Acauã and Canapu were used in the experiment; And the irrigation depths were based on fractions of the reference evapotranspiration estimated by the Penman-Monteith equation. The variables analyzed were: diameter, plant height, first branch insertion height with pod, shoot dry mass, pod weight, pod length, number of grains by pod, weight of one hundred grains, number of pods and number of branches with pods. There was not any significant interaction effect between irrigation depths and genotypes for any of the analyzed variables. The increase of the irrigation provided an increase in the number of branches, the height of insert of the first branch with pod and shoot dry mass of cowpea genotypes. The Canapu genotype highlighted for basic components related to grain yield.
\end{abstract}

Keywords: Reference evapotranspiration, water management, Vigna unguiculata.

\section{R E S U M O}

O feijão caupi tem potencial genético para alcançar produtividades elevadas quando em cultivo irrigado, porém a deficiência de água é um dos fatores limitantes da produção de grãos. Considerando que diferentes genótipos de feijão caupi respondem de formas distintas à aplicação de água e às condições climáticas nas quais estão submetidas, objetivou-se neste estudo, avaliar características fisiológicas e componentes de produção de feijão caupi sob diferentes lâminas de irrigação, no Submédio do Vale São Francisco. O experimento foi conduzido no campo experimental do DTCS/UNEB, Juazeiro, de julho a setembro de 2016. O delineamento experimental foi em blocos casualizados, esquema fatorial 2 x 5 (genótipos de feijão caupi x lâminas de irrigação), três repetições. Os genótipos utilizados foram BRS Acauã e Canapu; e as lâminas, determinadas com base em frações da evapotranspiração de referência estimada pela equação de PenmanMonteith. As variáveis analisadas foram: diâmetro, altura de planta, altura do primeiro ramo com vagem, massa seca da parte aérea, peso de vagem, comprimento 
de vagem, número de grãos por vagem, peso de cem grãos, número de vagens e número de ramos. Não houve efeito significativo de interação entre lâminas e genótipos de feijão para nenhuma das variáveis analisadas. O incremento da lâmina de irrigação proporcionou aumento no número de ramos, altura do primeiro ramo com vagem e massa seca da parte aérea dos genótipos de feijão caupi. O genótipo Canapu se destacou quanto aos componentes básicos relacionados à produtividade de grãos.

Palavras-Chave: Evapotranspiração de referência, manejo da água, Vigna unguiculata.

\section{Introdução}

O feijão caupi (Vigna unguiculata L. Walp.), chamado de feijão macassar, feijão fradinho, ou feijão de corda, é uma espécie de ampla adaptação, constitui uma das principais culturas para alimentação humana, principalmente nas regiões Norte e Nordeste do Brasil, por desempenhar importância fundamental no contexto socioeconômico das famílias de baixa renda que vivem nessas regiões (Cardoso \& Ribeiro, 2006).

A cultura do feijão caupi adapta-se bem a diversas condições edafoclimáticas, com predominância em regiões tropicais (Teixeira et al., 2010); podendo apresentar baixas produtividades quando é submetida às práticas de manejo inadequadas (Cardoso \& Ribeiro, 2006).

Como forma de elevar a produtividade da cultura, baixar os custos de produção e elevar a renda do produtor rural, é fundamental a adoção de tecnologias, tais como, o manejo adequado da irrigação (Oliveira et al., 2015). Locatelli et al. (2013) destacam que, a inserção de tecnologias inovadoras e conservacionistas, aliadas à irrigação pode levar a resultados economicamente satisfatórios para agricultores familiares e empresariais, garantindo emprego, renda e alimento a população. O manejo adequado da cultura do feijão caupi pode beneficiar as características fisiológicas da planta, influenciando no potencial produtivo (Bezerra et al., 2012).

O feijão caupi tem potencial genético para alcançar produtividades elevadas quando em cultivo irrigado, porém a deficiência de água é um dos fatores mais limitantes da produção de grãos, por quanto o estresse hídrico prejudica diversas processos fisiológicos da planta (Mendes et al., 2007). Mousinho, Andrade Junior \& Frizzone (2008) destacam a importância de um manejo criterioso do sistema solo-água-planta, para alcançar elevados retornos econômicos.

Considerando que diferentes genótipos de feijão caupi respondem de formas distintas à aplicação de água e às condições climáticas nas quais estão submetidas (Ramos et al., 2014), objetivou-se, no presente estudo, avaliar características fisiológicas e componentes de produção de feijão caupi, sob diferentes lâminas de irrigação, na região do Submédio do Vale do São Francisco.

\section{Material e Métodos}

$\mathrm{O}$ experimento foi conduzido na área experimental do Departamento de Tecnologia e Ciências Sociais-DTCS, da Universidade do Estado da Bahia-UNEB, no município de Juazeiro (Lat. 09 24' 50" S; Long. 40 30' 10" W; Alt. 368 $\mathrm{m})$, no período de julho a setembro de 2016. O clima da região, segundo a classificação climática de Köppen é do tipo Bswh', semiárido. O solo da área experimental foi classificado como Neossolo Flúvico.

A região onde o estudo foi conduzido é caracterizada por alta taxa de evaporação, devido, entre outros fatores, aos elevados valores de temperatura do ar, com valor médio anual em torno de $27^{\circ} \mathrm{C}$. Em Juazeiro e cidades vizinhas, as temperaturas mais amenas ocorrem no mês de julho e oscilam em torno de $22^{\circ} \mathrm{C}$; a média anual de precipitação é em torno de $600 \mathrm{~mm}$, com grande variabilidade espacial e temporal, período seco de junho a agosto, e chuvoso, de novembro a abril (Moura et al., 2006; Ramos et al., 2011).

Inicialmente foram coletadas amostras de solo da área experimental nas profundidades de 0$20 \mathrm{~cm}$ e de $20-40 \mathrm{~cm}$ e encaminhadas para análises químicas no Laboratório de Análises de Solo, Água e Calcário-LASAC do DTCS/UNEB. A área experimental foi preparada com aração e gradagem e instalado sistema de irrigação por gotejamento, com espaçamento de $20 \mathrm{~cm}$ entre gotejadores, vazão de $1,67 \mathrm{~L} \cdot \mathrm{h}^{-1}$ e pressão de serviço de $1,0 \mathrm{kgf.cm}^{-2}$. Foi realizado o teste de uniformidade de distribuição de água, através da metodologia proposta por Keller \& Karmeli (1974) (Equação 1), apresentando um coeficiente de uniformidade de distribuição de $96,5 \%$.

$$
C U D=100 \frac{\bar{x}}{\bar{X}}
$$


onde CUD é o coeficiente de uniformidade de distribuição de água (\%); $\bar{x}$ é a média de $1 / 4$ das vazões com menores valores, em litros.hora ${ }^{-1} ; \bar{X}$ é a média de todas as vazões dos emissores amostrados, em litros.hora ${ }^{-1}$.

A cultura estudada foi o feijão caupi, dois genótipos: cultivar BRS Acauã e Canapu. BRS Acauã é uma cultivar do grupo Canapu, desenvolvida pela Embrapa Semiárido, originada do cruzamento entre a BR 10 Gurgueia $x$ "Canapu", coletado na feira de Casa Nova, BA; é caracterizada pelo crescimento indeterminado e porte semiramador, possui ampla adaptação aos sertões da Bahia, Pernambuco e Piaú, com melhor comportamento em condições irrigadas (Santos, 2011). O genótipo Canapu foi adquirido na feira Cohab Massangano, Petrolina-PE; é de crescimento indeterminado e em função do seu ciclo curto, é conhecido popularmente como "Canapu Ligeiro", muito procurado pelos consumidores e produtores locais.

As sementes foram inoculadas no dia anterior ao plantio com estirpes de bactérias fixadoras de Nitrogênio (N), Bradyrhizobium ssp. - SEMIA 6463 e SEMIA 6462 - Feijão Caupi (Vigna unguiculata L. Walp.), na proporção de $300 \mathrm{ml}$ de inoculante, misturado em média com 5 $\mathrm{kg}$ de sementes. A semeadura do feijão foi realizada no dia 07 de Julho de 2016 em sistema de plantio direto, colocando em média 3 a 4 sementes por cova, a uma profundidade média de $2 \mathrm{~cm}$. Adotou-se a densidade de plantio de 100.000 plantas.ha $^{-1}$, com espaçamento de $0,50 \mathrm{~m}$ entre linhas e 5 plantas $\mathrm{m}^{-1}$. Quando as plantas se encontravam no estádio de desenvolvimento V3 (primeira folha trifoliolada, com folíolos expandidos), foi feito o desbaste, mantendo uma planta por cova.

O delineamento experimental adotado foi em blocos casualizados, esquema fatorial $2 \times 5$ (genótipos de feijão caupi $\mathrm{x}$ lâminas), dez tratamentos, três repetições. Cada unidade experimental com $18 \mathrm{~m}^{2}$ foi formada por três linhas de $18 \mathrm{~m}$ de comprimento, com espaçamento fixo de $0,50 \mathrm{~m}$ entre fileiras. Foi considerada como parcela útil a linha central, descartando as plantas da bordadura. Os dois genótipos de feijão caupi foram combinados com cinco lâminas de irrigação, obtidas com base em 50, 75, 100, 125 e $150 \%$ da evapotranspiração de referência (ETo), determinada diariamente a partir da equação de Penman-Monteith parametrizada pela FAO (Allen et al., 1998), com dados climáticos obtidos na estação meteorológica do DTCS/UNEB, localizada a cerca de $10 \mathrm{~m}$ da área experimental.
A partir dos dados de ETo, determinou-se a evapotranspiração da cultura (ETc) pela relação: $\mathrm{ETc}=\mathrm{Kc}$ ETo, em que Kc é o coeficiente de cultura. Foram utilizados valores de Kc para os diferentes estádios de desenvolvimento do feijão caupi sugeridos por Doorenbos \& Kassam (1979): inicial - 0,40 ; crescimento - 0,80 ; reprodutivo 1,20; e final - 0,75. Conhecendo a ETc e a eficiência do sistema de irrigação, determinou-se a lâmina a ser aplicado em cada tratamento. A diferenciação das lâminas de irrigação foi realizada quando boa parte das plantas se encontrava no estádio de crescimento, mais precisamente no subperíodo fenológico V4 (terceira folha trifoliolada, com folíolos expandidos); 15 dias após o plantio.

A adubação foi realizada com base nos resultados da análise de solo, seguindo o manual de recomendações de adubação para o Estado de Pernambuco, sendo feita apenas adubação de cobertura via fertirrigação, tendo como fonte de nutriente o fertilizante Sulfato de Potássio $\left(\mathrm{k}_{2} \mathrm{SO}_{4}\right), \quad$ com aplicação parcelada de aproximadamente $46 \mathrm{~kg} \cdot \mathrm{ha}^{-1}$, durante o ciclo da cultura. Para os demais tratos culturais, seguiu-se o comumente recomendado para a cultura do feijão.

Dentre o estande de plantas da parcela útil, foram selecionadas cinco plantas para avaliação das variáveis fisiológicas diâmetro $(\mathrm{mm})$ e altura $(\mathrm{cm})$, em oito mensurações, aos 17 , $24,31,38,45,52,59$ e 64 dias após o plantio (DAP); ao final do experimento, altura do primeiro ramo com vagem $(\mathrm{cm})$ e massa seca da parte aérea $(\mathrm{g})$. Foram avaliados ainda, os componentes de produção: peso de vagem (g), comprimento de vagem $(\mathrm{cm})$, número de grãos por vagem, peso de cem grãos $(\mathrm{g})$, número de vagens e número de ramos. Os dados foram submetidos à análise de variância com aplicação do teste F. Para interação significativa entre cultivares, as médias foram comparadas pelo teste de Tukey a 5\% de probabilidade; interação entre fatores e o fator lâmina isolado, a análise foi feita através de regressão polinomial, utilizando o software SISVAR, versão 5.6 (Ferreira, 2010).

\section{Resultados}

A colheita do cultivar BRS Acauã foi realizada aos 64 dias após o plantio (DAP), enquanto o Canapu, 78 DAP. Durante o ciclo da cultura, as lâminas aplicadas correspondentes as frações 50, 75, 100, 125 e $150 \%$ da ETo para o feijão BRS Acauã foram, respectivamente, 125,9; 188,$8 ; 251,7 ; 294,8$ e $335,4 \mathrm{~mm}$; para o Canapu: 141,$2 ; 221,6 ; 296,7 ; 370,9$ e $445,1 \mathrm{~mm}$. 
A condição climática observada durante o ciclo da cultura, em termos de valores médios de temperatura foi: para a cultivar BRS Acauã, média $24,9^{\circ} \mathrm{C}$, máxima $31,8^{\circ} \mathrm{C}$ e mínima $18,5^{\circ} \mathrm{C}$; para o Canapu, média de $25,2^{\circ} \mathrm{C}$, máxima $32,1^{\circ} \mathrm{C}$ e mínima $18,8^{\circ} \mathrm{C}$. Para todo o período experimental, a amplitude térmica foi de $13,3^{\circ} \mathrm{C}$; a temperatura atingiu valores mínimos diários de até $14,2^{\circ} \mathrm{C}$ e máximos de $36,8^{\circ} \mathrm{C}$ (Figura 1).

Durante todo o ciclo da cultura, a precipitação ocorrida foi de apenas $0,50 \mathrm{~mm}$; a radiação solar foi em média $19,7 \mathrm{MJ} \cdot \mathrm{m}^{-2} \cdot \mathrm{d}^{-1}$, com variação de 13,1 a $24,4 \quad \mathrm{MJ} \cdot \mathrm{m}^{-2} \cdot \mathrm{dia}^{-1}$; e a velocidade média do vento, $3,2 \mathrm{~m} \cdot \mathrm{s}^{-1}$.

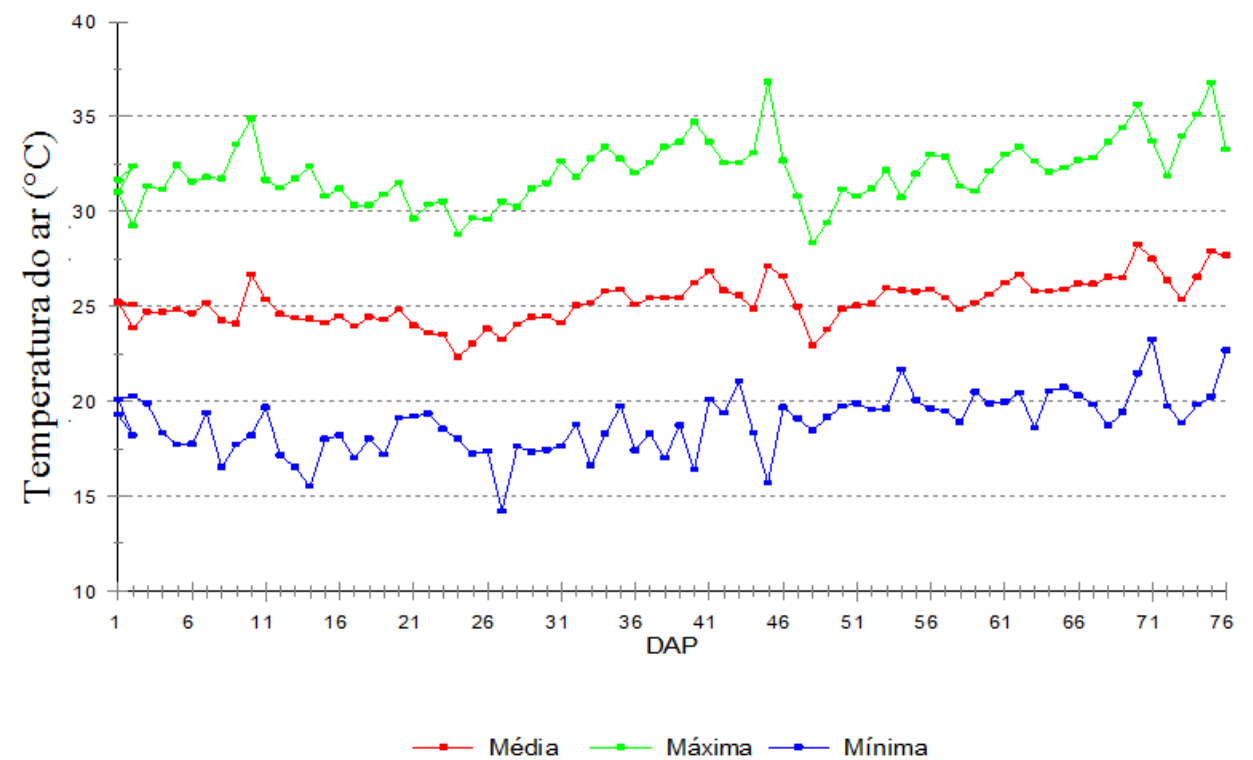

Figura 1. Temperatura do ar média, máxima durante o ciclo de feijão caupi, de 07 de julho a 22 de setembro de 2016, em Juazeiro-BA.

A análise de variância (Tabela 4) aplicada para os diferentes períodos de observação revelou que não houve efeito significativo de interação entre lâminas e genótipos de feijão para nenhuma das variáveis fisiológicas analisadas. Considerando-se o fator isolado, para genótipo, observou-se efeito significativo na massa seca da parte aérea e na altura e diâmetro de planta em alguns dos períodos analisados; e efeito das lâminas para altura do primeiro ramo com vagem e para massa seca da parte aérea.

Tabela 4. Resumo da análise de variância para as variáveis: altura da planta, diâmetro do caule, número de ramos por planta (NRP), número de grãos por vagem (NGV), número de vagens por planta (NVP), peso de 100 grãos (P100G), comprimento de vagem (CV), peso de vagens (PV), massa seca da parte aérea (MSPA), altura do $1^{\circ}$ ramo com vagem $\left(\mathrm{A} 1^{\circ} \mathrm{R}\right)$, de genótipos $(\mathrm{G})$ de feijão caupi, em função de lâminas de irrigação (L).

\begin{tabular}{|c|c|c|c|c|c|c|c|c|c|}
\hline \multirow{3}{*}{ FV } & \multicolumn{8}{|c|}{ QUADRADO MÉDIO } & \multirow[b]{3}{*}{64 DAP } \\
\hline & \multicolumn{8}{|c|}{ Altura da planta } & \\
\hline & GL & $17 \mathbf{D A P}$ & $24 \mathrm{DAP}$ & 31 DAP & 38 DAP & 45 DAP & $52 \mathrm{DAP}$ & 59 DAP & \\
\hline $\mathrm{L}$ & 4 & $0,876 \mathrm{~ns}$ & $1,627 \mathrm{~ns}$ & $2,917 \mathrm{~ns}$ & $2,643 \mathrm{~ns}$ & $4,530 \mathrm{~ns}$ & $62,322 \mathrm{~ns}$ & $75,780 \mathrm{~ns}$ & $81,514 \mathrm{~ns}$ \\
\hline $\mathrm{G}$ & 1 & $16,265^{* *}$ & $17,404 * *$ & $33,454 *$ & $* 2,017 \mathrm{~ns}$ & $0,218 \mathrm{~ns}$ & $1703,738 *$ & $1719,449 * *$ & $1367,145^{* *}$ \\
\hline $\mathrm{L} \times \mathrm{G}$ & 4 & $0,038 \mathrm{~ns}$ & $0,639 \mathrm{~ns}$ & $1,198 \mathrm{~ns}$ & $1,186 \mathrm{~ns}$ & $1,571 \mathrm{~ns}$ & $44,240 \mathrm{~ns}$ & $51,554 \mathrm{~ns}$ & $44,867 \mathrm{~ns}$ \\
\hline $\mathrm{CV} \%$ & - & 10,19 & 11,39 & 9,30 & 10,66 & 8,35 & 44,70 & 34,32 & 26,58 \\
\hline \multicolumn{10}{|c|}{ Diâmetro do caule } \\
\hline $\mathrm{L}$ & 4 & $0,064 \mathrm{~ns}$ & $0,087 \mathrm{~ns}$ & $0,440 \mathrm{~ns}$ & $0,714 \mathrm{~ns}$ & $0,846 \mathrm{~ns}$ & $0,500 \mathrm{~ns}$ & $0,591 \mathrm{~ns}$ & $0,451 \mathrm{~ns}$ \\
\hline $\mathrm{G}$ & 1 & $0,198^{*}$ & $0,155 \mathrm{~ns}$ & $0,761 \mathrm{~ns}$ & $4,048^{*}$ & $2,048 \mathrm{~ns}$ & $0,288 \mathrm{~ns}$ & $0,736 \mathrm{~ns}$ & $2,187 \mathrm{~ns}$ \\
\hline $\mathrm{L} \times \mathrm{G}$ & 4 & $0,028 \mathrm{~ns}$ & $0,207 \mathrm{~ns}$ & $0,101 \mathrm{~ns}$ & $0,653 \mathrm{~ns}$ & $0,459 \mathrm{~ns}$ & $0,630 \mathrm{~ns}$ & $0,722 \mathrm{~ns}$ & $0,910 \mathrm{~ns}$ \\
\hline $\mathrm{CV} \%$ & - & 7,14 & 9,48 & 11,70 & 16,72 & 13,37 & 17,06 & 13,78 & 11,26 \\
\hline $\mathrm{FV}$ & GL & NRP & NGV & NVP & P100G & $\mathbf{C V}$ & PV & MSPA & $\mathbf{A 1}^{\circ} \mathbf{R}$ \\
\hline $\mathrm{L}$ & 4 & $13,365^{*}$ & $0,455 \mathrm{~ns}$ & $\overline{50,408 \mathrm{~ns}}$ & $0,758 \mathrm{~ns}$ & $0,224 \mathrm{~ns}$ & $0,121 \mathrm{~ns}$ & $441,151 * *$ & $11,724 *$ \\
\hline $\mathrm{G}$ & 1 & $56,033 * *$ & $0,481 \mathrm{~ns} \quad 3$ & $320,133 * *$ & $0,660 \mathrm{~ns}$ & $23,267 * *$ & $0,023 \mathrm{~ns}$ & $1682,553 * *$ & $0,324 \mathrm{~ns}$ \\
\hline
\end{tabular}


$\begin{array}{lllllllll}\mathrm{L} x \mathrm{G} & 4 & 1,493 \mathrm{~ns} & 0,156 \mathrm{~ns} & 3,746 \mathrm{~ns} & 0,441 \mathrm{~ns} & 0,174 \mathrm{~ns} & 0,026 \mathrm{~ns} & 19,984 \mathrm{~ns}\end{array} \quad 3,738 \mathrm{~ns}$

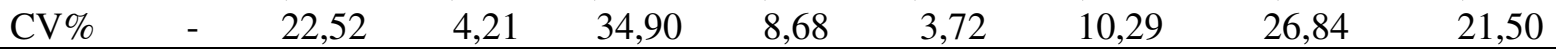

${ }^{\mathrm{ns}}$ Não significativo; $*$ significativo a $5 \%$ de probabilidade; $* *$ significativo a $1 \%$ de probabilidade pelo teste $\mathrm{F}$.

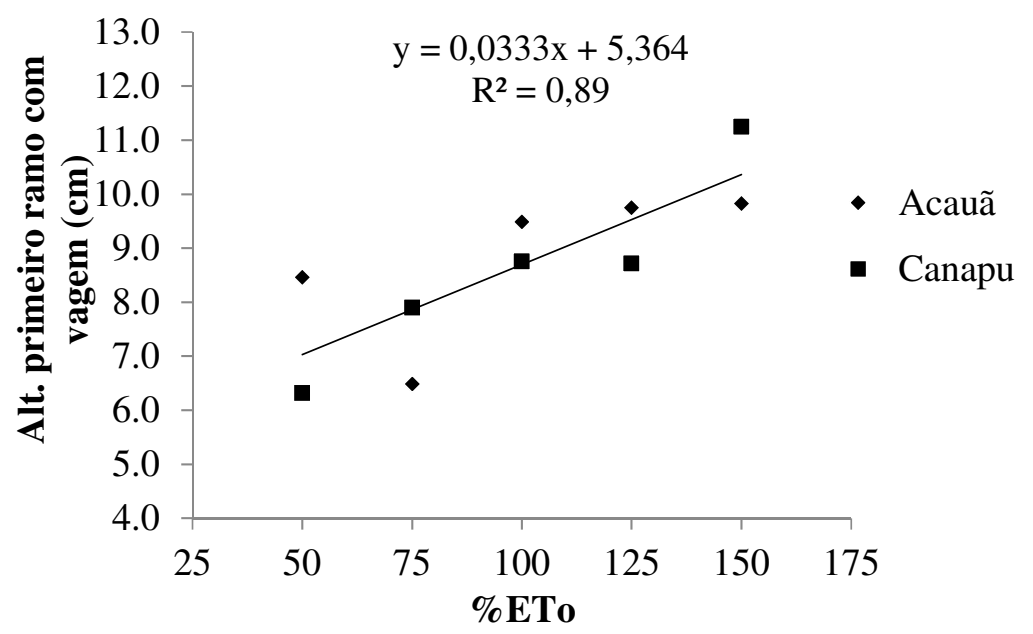

Figura 2. Altura do primeiro ramo com vagem para genótipos de feijão caupi, em função das lâminas de irrigação correspondentes a percentuais da ETo.

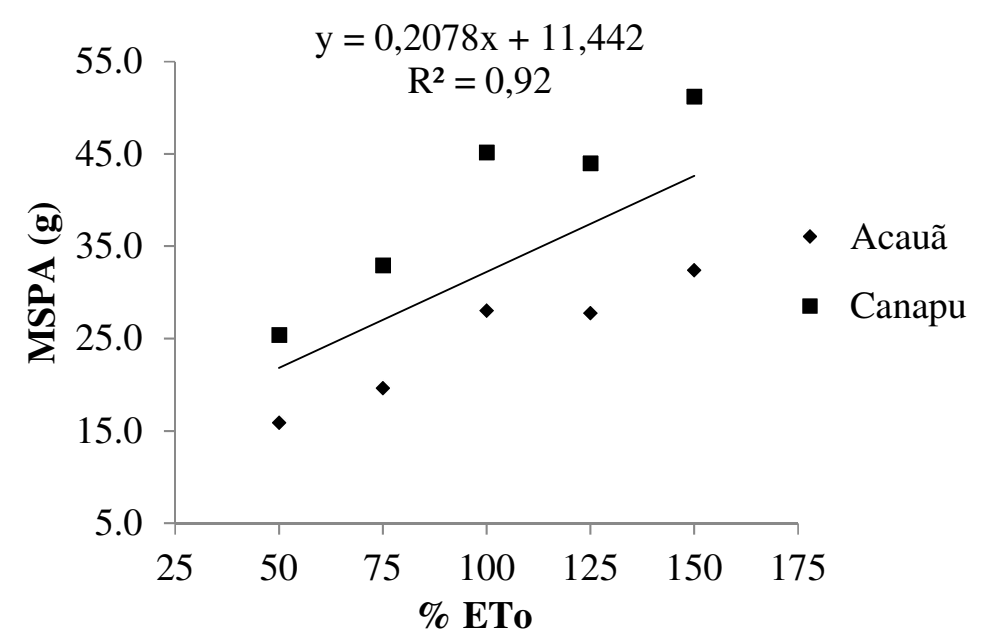

Figura 3. Massa seca da parte aérea para os genótipos de feijão caupi, BRS Acauã e Canapu, em função das lâminas de irrigação correspondentes a percentuais da ETo.

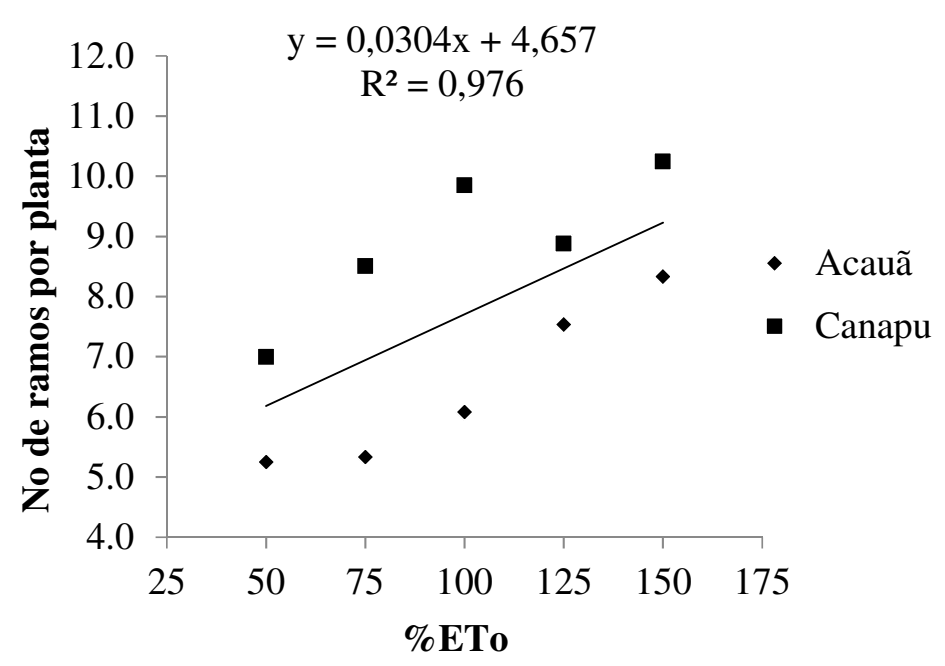

Figura 4. Número de ramos por planta para os genótipos de feijão caupi, BRS Acauã e Canapu, em função das lâminas de irrigação correspondentes a percentuais da ETo. 
Para os componentes de produção, a análise de variância (Tabela 4) revelou que não houve efeito significativo de interação entre lâminas e genótipos de feijão caupi. Foi observado efeito das lâminas apenas para o número de ramos por planta e para os genótipos, efeito significativo para o comprimento de vagem, número de ramos e número de vagens por planta.

Percebe-se, na Tabela 1, a diferença de comportamento entre os genótipos ao longo do tempo; a cultivar BRS Acauã atinge a fase reprodutiva mais rápido e a encerra em um menor tempo, quando comparada ao genótipo Canapu. A última análise realizada aos 64 DAP representa o fim do ciclo (colheita) para a BRS Acauã, após esse período, o feijão Canapu permanece em campo até os 78 DAP. Isso indica diferentes exigências térmicas entre os genótipos.

Tabela 1. Fases fenológicas e valores médios da temperatura do ar correspondentes a cada um dos oito períodos de observações das variáveis fisiológicas.

\begin{tabular}{lllccc}
\hline \multirow{2}{*}{ DAP } & & Fases fenológicas & \multicolumn{2}{c}{ Temperatura do ar $\left(\mathbf{0}^{\mathbf{C}} \mathbf{C}\right)$} \\
& BRS Acauã & Canapu & Média & Máxima & Mínima \\
\hline 17 & V3 & V3 & 24,8 & 31,8 & 18,2 \\
24 & V4 & V4 & 24,1 & 30,5 & 18,3 \\
31 & Pré-floração & V4 & 23,6 & 30,2 & 17,0 \\
38 & Pré-floração & Pré-floração & 25,2 & 32,6 & 18,1 \\
45 & Formação de vagem & Pré-floração & 25,8 & 33,4 & 18,7 \\
52 & Enchimento de grãos & Floração & 25,0 & 31,4 & 18,8 \\
59 & Maturação & Formação de vagem & 25,7 & 32,0 & 20,0 \\
64 & Maturação & Enchimento de grãos & 25,7 & 32,3 & 19,7 \\
\hline
\end{tabular}

Considerando a altura de planta, exceto nas análises de 38 e 45 DAP, nos diferentes períodos analisados, observou-se diferença significativa ao considerar o fator genótipo (Tabela 2). Para os três primeiros períodos, as plantas do cultivar BRS Acauã apresentaram maior altura em relação ao Canapu, porém, para os períodos 38 e 45 DAP, em que foram observados valores mais elevados da temperatura, o crescimento do Canapu foi similar ao da BRS Acauã, atingindo a fase fenológica pré-floração.

Tabela 2. Médias de altura e diâmetro para genótipos de feijão caupi, BRS Acauã e Canapu, ao longo do ciclo de desenvolvimento da cultura.

\begin{tabular}{|c|c|c|c|c|c|c|c|c|}
\hline \multirow{2}{*}{$\begin{array}{l}\text { Genótipo } \\
\text { DAP }\end{array}$} & \multicolumn{8}{|c|}{ Altura da planta $(\mathrm{cm})$} \\
\hline & 17 & 24 & 31 & 38 & 45 & 52 & 59 & 64 \\
\hline BRS Acauã & $7,34 \mathrm{a}$ & $9,65 \mathrm{a}$ & $12,24 \mathrm{a}$ & $13,99 \mathrm{a}$ & $19,60 \mathrm{a}$ & $40,56 a$ & 47,41a & $53,27 \mathrm{a}$ \\
\hline Canapu & $5,87 \mathrm{~b}$ & $8,13 \mathrm{~b}$ & $10,13 b$ & $13,48 \mathrm{a}$ & $19,77 \mathrm{a}$ & $25,49 \mathrm{~b}$ & $32,27 b$ & $39,77 \mathrm{~b}$ \\
\hline \multirow{2}{*}{$\mathrm{CV}(\%)$} & 10,19 & 11,39 & 9,30 & 10,66 & 8,35 & 44,70 & 34,32 & 26,58 \\
\hline & \multicolumn{8}{|c|}{ Diâmetro do caule (mm) } \\
\hline DAP & 17 & 24 & 31 & 38 & 45 & 52 & 59 & 64 \\
\hline BRS Acauã & $2,62 b$ & $2,99 a$ & $4,06 \mathrm{a}$ & $5,15 b$ & $6,06 a$ & 7,58a & $8,18 \mathrm{a}$ & $9,00 \mathrm{a}$ \\
\hline Canapu & $2,78 \mathrm{a}$ & $3,13 \mathrm{a}$ & $4,48 \mathrm{a}$ & $5,88 \mathrm{a}$ & $6,58 \mathrm{a}$ & 7,38a & $8,50 \mathrm{a}$ & $9,54 \mathrm{a}$ \\
\hline $\mathrm{CV}(\%)$ & 7,14 & 9,48 & 11,70 & 16,72 & 13,37 & 17,06 & 13,78 & 11,26 \\
\hline
\end{tabular}

* Letras minúsculas iguais na vertical não diferem entre si; DAP = dias após plantio.

Considerando a massa seca da parte aérea (MSPA), os efeitos das diferentes lâminas aplicadas, através da análise de regressão polinomial, apresentaram ajuste linear para os genótipos estudados (Figura 3). Considerando a menor e maior lâmina aplicada, respectivamente, a massa seca da parte aérea do cultivar BRS Acauã variou de 15,87 a 32,42 g e a do Canapu, de 25,37 a 51,17 g. Percebe-se, portanto, maior produção de massa seca do Canapu comparada ao BRS Acauã; em termos de média, considerando todas as lâminas: BRS Acauã, 24,73 g e Canapu, $39,71 \mathrm{~g}$, diferindo significativamente (Tabela 3).

Tabela 3. Médias para as variáveis: número de ramos por planta (NRP), comprimento de vagem $(\mathrm{CV})$, número de vagens por planta (NVP) e massa seca da parte aérea (MSPA) de genótipos de feijão caupi.

\begin{tabular}{lcccc}
\hline Genótipo & NRP & $\begin{array}{c}\text { CV } \\
(\mathbf{c m})\end{array}$ & NVP & $\begin{array}{c}\text { MSPA } \\
(\mathbf{g})\end{array}$ \\
\hline $\begin{array}{l}\text { BRS } \\
\text { Acauã }\end{array}$ & $7,01 \mathrm{~b}$ & $20,62 \mathrm{a}$ & $8,63 \mathrm{~b}$ & $24,73 \mathrm{~b}$
\end{tabular}




\begin{tabular}{lcccc} 
Canapu & $9,75 \mathrm{a}$ & $18,86 \mathrm{~b}$ & $15,16 \mathrm{a}$ & $39,71 \mathrm{a}$ \\
\hline $\mathrm{CV}(\%)$ & 22,52 & 3,72 & 34,90 & 26,84 \\
\hline
\end{tabular}

Nos resultados encontrados para MSPA no presente estudo, verificou-se que houve um aumento significativo da massa seca total com a aplicação da maior lâmina de irrigação.

Considerando a altura do primeiro ramo com vagem, os efeitos das diferentes lâminas aplicadas, através da análise de regressão polinomial, revelaram um ajuste linear $(\mathrm{P}<0,05)$ para os genótipos de feijão caupi (Figura 2). Percebe-se que essa variável aumentou com o incremento das lâminas de irrigação. Canapu aumentou de 6,33 cm (menor lâmina) para 11,25 cm (maior lâmina), ou seja, um aumento de 77,73\%; a média, considerando todas as lâminas, foi de $8,6 \mathrm{~cm}$. A cultivar BRS Acauã aumentou de $8,46 \mathrm{~cm}$ (menor lâmina) para $9,83 \mathrm{~cm}$ (maior lâmina), correspondendo a um aumento de 16,19\%; a média foi de $8,8 \mathrm{~cm}$.

Constatou-se através da regressão polinomial, ajuste linear para efeitos das diferentes lâminas aplicadas sobre número de ramos por planta dos genótipos de feijão caupi (Figura 4). Para cultivar BRS Acauã, o número de ramos correspondente a menor lâmina foi de 5,25, e para maior, 8,33 , ou seja, aumento de $58,67 \%$.

\section{Discussão}

As diferenças no valor das laminas de irrigação certamente estão associadas à cultivar, à época de condução do experimento, à condição climática local, bem como, ao método de estimativa da ETo utilizado.

As diferenças no ciclo dos genótipos são explicadas em função do maior número de dias requerido pelo feijão Canapu, para as vagens atingirem a coloração típica de vagens madura.

A variação de temperatura média observada durante a condução do experimento está dentro da faixa indicada como ideal para o feijão caupi 20 a $30^{\circ} \mathrm{C}$ (Santos et al., 2010).

As temperaturas observadas para cada período foram ligeiramente superiores àquelas consideradas ideais entre a emergência e a maturação fisiológica para a cultura, 12 a $30^{\circ} \mathrm{C}$ (Didonet \& Silva, 2004). Maiores temperaturas observadas aos 38 e 45 DAP podem ter submetido às plantas, em alguns momentos, a estresse térmico; e certamente contribuíram para acelerar o processo de formação de vagem para cultivar BRS Acauã. De acordo com Didonet \& Silva (2004), temperaturas altas, que geralmente estão associadas à alta radiação, diminuem o número de dias para o florescimento e reduzem o ciclo de vida do fejoeiro. Khan et al. (2010) ressaltam que o feijoeiro é capaz de se recuperar após o estresse térmico na fase de início de floração.

A BRS Acauã, aos 45 DAP, certamente não só em função da condição térmica, mas também de características do cultivar, acelera seu ciclo, apresentando-se na fase de formação de vagens, a partir desse período, seu crescimento volta a ser superior ao do Canapu, atingindo aos 64 DAP a fase de maturação, enquanto o Canapu, ainda se encontrava na fase de enchimento de grãos. A média de altura da cultivar BRS Acauã aos 64 DAP (colheita) foi próxima à encontrada por Locatelli et al. (2013) para feijão caupi produzido sob diferentes lâminas de irrigação no cerrado de Roraima, 55,3 cm; média de altura de planta, considerada pelos autores, como adequada para a colheita mecanizada.

Considerando o diâmetro do caule, foi observada diferença significativa entre os genótipos com DAP entre 17 e 38 (Tabela 2), com o Canapu apresentando maior diâmetro em relação à BRS Acauã. Aos 64 DAP (colheita da BRS Acauã), as médias observadas, quanto ao diâmetro do caule, foram ligeiramente inferiores àquelas encontradas por Bezerra et al. (2012) para a cultivar BRS Guariba, 11,89 mm, em Alvorada do Gurgueia-PI.

Os valores observados neste estudo para a altura do primeiro ramo com vagem foram abaixo daqueles desejados para lavouras tecnificadas. Conforme destacam Silva, Abreu \& Ramalho (2009), a demanda por cultivares, com arquitetura de planta que facilite os tratos culturais e a colheita, é bastante elevada. Plantas com o porte mais ereto têm sido uma das principais exigências, tanto dos empresários rurais quanto dos agricultores familiares.

Segundo Silva et al. (2014), a altura de inserção de primeiro ramo com vagem é uma característica importante na obtenção de plantas com tipo ideal para a agricultura moderna, favorecendo a colheita e a qualidade dos grãos, pois, plantas com maior altura de inserção apresenta menores riscos de apodrecimento de vagem pelo contato com o solo. Além disso, Horn et al. (2000) ressaltam que um dos maiores problemas das lavouras tecnificadas de feijão caupi são as perdas no momento da colheita, ocasionadas pela baixa altura de inserção das vagens.

A maior produção de massa seca do Canapu, certamente está associada às características do genótipo, como o número de dias requerido para as vagens atingirem o estágio de maturação. Didonet \& Silva (2004) ressalvam que cultivares com maior período em campo têm um maior tempo para acúmulo de biomassa. 
O teor de massa seca da parte aérea pode ser considerado um indicador de produtividade, pois em lâminas de irrigação que promovem o estresse hídrico, a planta fecha os estômatos para manter o potencial de água na folha, assim reduz a assimilação de $\mathrm{CO}_{2}$ e, por conseguinte os fotoassimilados, e dessa forma os teores de massa seca da planta, bem como o crescimento e a produtividade podem ser reduzidos (Oliveira et al., 2005).

Em se tratando do Canapu, a variação foi de 7,0 a 10,25 , correspondente a menor e maior lâmina, respectivamente, representando um aumento de $46,43 \%$. Constata-se, portanto, que maior disponibilidade de água no solo proporciona maior desenvolvimento da cultura. Por ser uma característica importante em que se relaciona com o número de vagens, uma redução no número de ramos pode causar diminuição no número de gemas reprodutivas (Bezerra et al., 2008).

A redução no número de ramos está diretamente relacionada à redução do número de vagens, afetando diretamente a produtividade; essa redução é atribuída em resposta à maior densidade de plantas (Mendes et al., 2005; Bezerra et al., 2009).

Quanto aos efeitos do fator genótipos sobre o número de ramos por planta, comprimento de vagem e número de vagens por planta, verificou-se diferença significativa entre as médias proporcionadas pelos genótipos. Para BRS Acauã, observa-se um menor número de ramos por planta e, consequentemente, um menor número de vagens por planta, corroborando a afirmação de Bezerra et al. (2008) que, uma redução no número de ramos pode causar diminuição no número de gemas reprodutivas. $\mathrm{O}$ número de vagens por planta encontrado para o Canapu $(15,16)$ foi superior, e para a cultivar BRS Acauã $(8,63)$ inferior, àqueles encontrados por Locatelli et al. (2014), para as cultivares BRS Guariba $(9,498)$, BRS Novaera $(12,844)$ e BRS Pajeú (11,084). Lacatelli (2013) discorre que a diferença no número de vagens por planta entre cultivares, pode estar relacionado às características de cada cultivar. De acordo com Silva et al. (2007), o número de vagens por planta é o componente básico que mais se relaciona com a produtividade de grãos, sendo muito influenciado pelo ambiente.

A cultivar BRS Acauã apresentou maior comprimento de vagem, 20,62 $\mathrm{cm}$, comparada com o Canapu, $18,86 \mathrm{~cm}$; esses valores estão próximos daqueles encontrados por Santos et al. (2000) para feijão caupi $(19,7$ a $22,6 \mathrm{~cm})$. Os autores afirmam que um maior comprimento de vagem possibilita uma maior quantidade de locus, proporcionando maior quantidade de grãos por vagem, porém, é preferível plantas com vagens de tamanho curto ou intermediário, pois, na presença de irrigação, estas podem ter maior contato com o solo úmido, facilitando o ataque das vagens $\mathrm{e}$ grãos por microrganismos, prejudicando a produção e, consequentemente, a produtividade da cultura.

\section{Conclusão}

O incremento da lâmina de irrigação proporcionou aumento no número de ramos, altura do primeiro ramo com vagem e peso da massa seca da parte aérea dos genótipos de feijão caupi.

O genótipo Canapu se destacou quanto aos números de vagens e de ramos por planta e matéria seca da parte aérea, componentes básicos relacionados à produtividade de grãos.

\section{Agradecimentos}

À Universidade do Estado da Bahia pela disponibilidade de suas instalações.

\section{Referências}

ALLEN, R.G.; PEREIRA, L.S.; RAES, D.; SMITH, M. 1998. Crop evapotranspiration: guidelines for computing crop water requirements. Rome: FAO. Irrigation and Drainage Paper, n. 56. 300p.

AZEVEDO, B. M.; FERNANDES, C. N. V.; PINHEIRO, J. A.; BRAGA, E. S.; CAMPÊLO, A. R.; VIANA, T. V. A.; CAMBOIM NETO, L. F.; MARINHO, A. B. 2011. Efeitos de lâminas de irrigação na cultura do feijão vigna de cor preta. Agropecuária Técnica, v. 32, n. 1, p. 152-159.

BEZERRA, A. A. C.; NETO, F. A.; NEVES, A. C.; MAGGIONI, K. 2012. Comportamento morfoagronômico de feijão caupi, cv. BRS Guariba, sob diferentes densidades de plantas. Revista de Ciâncias Agrárias, v. 55, n. 3, p. 184189.

BEZERRA, A. A. C.; TÁVORA, F. J. A. F.; FREIRE FILHO, F. R.; RIBEIRO, V. Q. 2009. Características de dossel e de rendimento em feijão-caupi ereto em diferentes densidades populacionais. Pesquisa Agropecuária Brasileira, v. 44 , n. 10, p. 1239-1245.

BEZERRA, A. A. C.; TÁVORA, F. J. A. F.; FREIRE FILHO, F. R.; RIBEIRO, V. Q. 2008. Morfologia e produção de grãos em linhagens modernas de feijão-caupi submetidas a diferentes 
densidades populacionais. Revista de Biologia e Ciências da Terra, v. 8, p. 85-93.

CARDOSO, M. J.; RIBEIRO, V. Q. 2006. Desempenho agronômico do feijão-caupi, cv. Rouxinol, em função de espaçamentos entre linhas e densidades de plantas sob regime de sequeiro. Revista Ciência Agronômica, v. 37, n. 01, p. 102-105.

COELHO, D. S.; MARQUES, M. A. D.; SILVA, J. A. B.; GARRIDO, M. S.; CARVALHO, P. G. S. 2014. Respostas fisiológicas em variedades de feijão caupi submetidas a diferentes níveis de sombreamento. Revista Brasileira de Biociências, v. 12 , n. 1 , p. 14-19.

DIDONET, A. D.; SILVA, S. C. 2004. Elementos climáticos e produtividade do feijoeiro. Informe Agropecúario, v. 25, n. 223, p. 13-15.

DOORENBOS, J.; KASSAM, A. H. 1979. Yield response to water. Irrigation and Drainage Paper, 33. Roma: FAO, 193p.

FERREIRA, D. F. 2010. SISVAR, Versão 5.6 (Build 86) DEX/UFLA.

HORN, F. L.; SCHUCH, L. O. B.; SILVEIRA, E. P.; ANTUNES, I. F.; VIEIRA, J. C.; MARCHIORO, G.; MEDEIROS, D. F.; SCHWENGBER, J. E. 2000. Avaliação de espaçamentos e populações de plantas de feijão visando à colheita mecanizada direta. Pesquisa agropecuária brasileira, v. 35, n. 1, p. 41-46.

KELLER, J.; KARMELI, D. 1974. Trickle irrigation design parameters. Transactions of the ASAE, v. 17, p. 678-684.

KHAN, H. R.; PAULL, J. G.; SIDDIQUE, K. H. M.; STODDARD, F. L. 2010. Faba bean breeding for drought-affected environments: a physiological and agronomic perspective. Field Crops Research, v. 115, p. 27-286.

LEITE, M. L.; VIRGENS FILHO, J. S. 2004. Produção de matéria seca em plantas de caupi (Vigna unguiculata (L.) Walp) submetidas a déficits hídricos. Publicatio UEPG Ciências Exatas e da Terra, Ciências Agrárias e Engenharias, v. 10, n. 01, p. 43-51.

LOCATELLI, V. E. R.; MEDEIROS, R. D.; SMIDERLE, O. J.; ALBUQUERQUE, J. A. A.; ARAÚJO, W. F. 2013. Características fisiológicas do feijão-caupi sob diferentes lâminas de irrigação no cerrado de Roraima. In: II Congresso Nacional de Feijão Caupi-CONAC, Recife, Pernambuco.

LOCATELLI, V. E. R.; MEDEIROS, R. D.; SMIDERLE, O. J.; ALBUQUERQUE, J. A. A.; ARAÚJO, W. F.; SOUZA, K. T. S. 2014. Componentes de produção, produtividade e eficiência da irrigação do feijão-caupi no cerrado de Roraima. Revista Brasileira de Engenharia Agrícola e Ambiental, v. 18, n. 6, p. 574-580.

MENDES, R. M. S.; TÁVORA, F. J. A. F.; PINHO, J. L. N.; PITOMBEIRAS, J. B. 2005. Alterações na relação fonte-dreno em feijão-decorda submetido a diferentes densidades de plantas. Revista Ciência Agronômica, v. 36, n. 1, p. 82-90.

MENDES, R. M. S.; TÁVORA, F. J. A. F.; PINHO, J. L. N.; PITOMBEIRA, J. B. 2007. Relações fonte-dreno em feijão-de-corda submetido à deficiência hídrica. Revista Ciência Agronômica, v. 38, p. 95-103.

MOUSINHO, F. E. P.; ANDRADE JUNIOR, A. S.; FRIZZONE, J. A. F. 2008. Viabilidade econômica do cultivo irrigado do feijão-caupi no Estado-caupi no Estado do Piauí. Acta Sci. Agron., v. 30, n. 1, p. 139-145.

OLIVEIRA, A. D.; FERNANDES, E. J.; RODRIGUES, T. J. D. 2005. Condutância estomática como indicador de estresse hídrico em Feijão. Revista Engenharia Agrícola, v. 25, p. 8695.

OLIVEIRA, F. A.; MEDEIROS, J. F.; ALVES, R. C.; LIMA, L. A.; SANTOS, S. T.; RÉGIS, L. R. L. 2015. Produção de feijão caupi em função da salinidade e regulador de crescimento. Revista Brasileira de Engenharia Agrícola e Ambiental, v. 19, n. 11, p. 1049-1056.

RAMOS, C. M. C.; SILVA, A. F.; SARTORI, A. A. C.; ZIMBACK, C. R. L.; BASSOI, L. H. 2011. Modelagem da variação horária da temperatura do ar em Petrolina, PE, e Botucatu, SP. Revista Brasileira de Engenharia Agrícola e Ambiental, v. 15, p. 959-965.

RAMOS, H. M. M; BASTOS, E. A.; CARDOSO, M. J.; RIBEIRO, V. Q.; NASCIMENTO, F. N. 2014. Produtividade de grãos verdes do feijãocaupi sob diferentes regimes hídricos. Engenharia Agrícola, v. 34, n. 4, p. 683-694. 
SANTOS, C. A. F.; ARAÚJO, F. P.; MENEZES, E. A. 2000. Comportamento produtivo de caupi em regimes irrigado e de sequeiro em Petrolina e Juazeiro. Pesquisa Agropecuária Brasileira, v. 35, n. 11, p. 2229-2234.

SANTOS, C.A.F. 2011. BRS Tapaihum, BRS Carijó e BRS Acauã: novas cultivares de feijão caupi para o vale do São Francisco. In: Congresso Brasileiro de Olericultura, 51. Anais... Viçosa: ABH. pp. 3086-3094.

SILVA, A. C.; MORAIS, O. M. L.; SANTOS, J. L.; D'AREDE, L. O.; SILVA, C. J.; ROCHA, M. M. 2014. Estimativa de parâmetros genéticos em Vigna unguiculata. Revista de Ciências Agrárias, v. 37 , n. 4 , p. 399-407.

SILVA, A. O.; LIMA E. A.; MENEZES, H. E. A. 2007. Rendimento de grãos de feijão (Phaseolus vulgaris $\mathrm{L}$.), cultivado em diferentes densidades de plantio. Revista Fafibe, n. 3, p. 1-5.
SILVA, C.A.; ABREU, A.F.B.; RAMALHO, M.A.P. 2009. Associação entre arquitetura de planta e produtividade de grãos em progênies de feijoeiro de porte ereto e prostrado. Pesquisa Agropecuária Brasileira, v. 44, n. 12, p. 16471652.

SILVA, V. P. R.; CAMPOS, J. H. B. C.; SILVA, M. T.; AZEVEDO, P. V. 2010. Impact of global warming on cowpea bean cultivation in northeastern Brazil. Agricultural Water Management, v. 97, n. 1, p. 1760-1768.

TEIXEIRA, I. R.; SILVA, G. C.; OLIVEIRA, J. P. R.; SILVA, A. G.; PELÁ, A. 2010. Desempenho agronômico e qualidade de sementes de cultivares de feijão-caupi na região do cerrado. Revista Ciência Agronômica, v. 41, n. 2, p. 300307. 